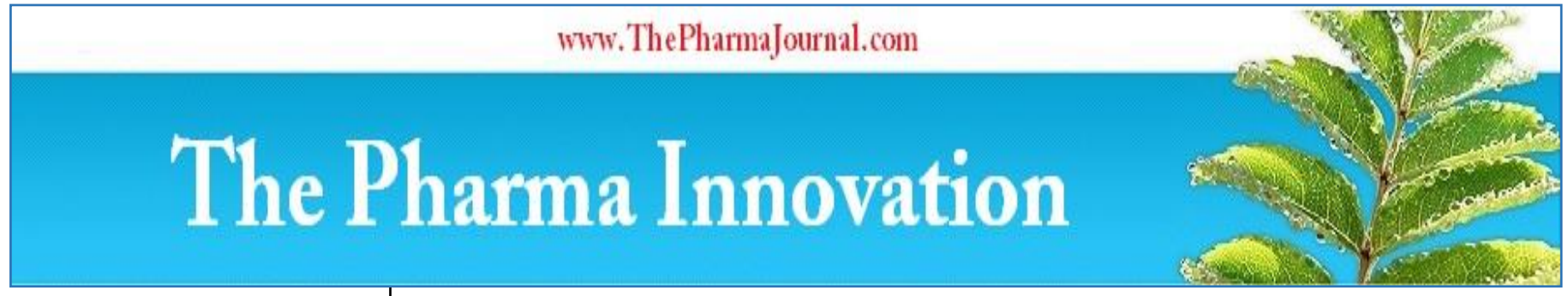

ISSN (E): 2277 - 7695

ISSN (P): 2349-8242

NAAS Rating: $\mathbf{5 . 0 3}$

TPI 2020; 9(3): 520-523

(C) 2020 TPI

www.thepharmajournal.com

Received: 07-01-2020

Accepted: 09-02-2020

\section{Chauhan PM}

Department of Veterinary

Gynaecology \& Obstetrics, Dr. V. M.

Jhala Clinical Complex, Deesa,

College of Veterinary Science and

Animal husbandry,

Sardarkrushinagar Dantiwada

Agricultural University,

Sardarkrushinagar, Gujarat, India

\section{Sahu AD}

Department of Veterinary

Gynaecology \& Obstetrics, Dr. V. M.

Jhala Clinical Complex, Deesa,

College of Veterinary Science and

Animal husbandry,

Sardarkrushinagar Dantiwada

Agricultural University,

Sardarkrushinagar, Gujarat, India

Nakhashi HC

Department of Veterinary

Gynaecology \& Obstetrics, Dr. V. M.

Jhala Clinical Complex, Deesa,

College of Veterinary Science and

Animal husbandry,

Sardarkrushinagar Dantiwada

Agricultural University,

Sardarkrushinagar, Gujarat, India

Jogdand DT

Department of Veterinary

Gynaecology \& Obstetrics, Dr. V. M.

Jhala Clinical Complex, Deesa,

College of Veterinary Science and

Animal husbandry,

Sardarkrushinagar Dantiwada

Agricultural University,

Sardarkrushinagar, Gujarat, India

\section{Sodagar BN}

Department of Veterinary Surgery and Radiology, Dr. V. M. Jhala Clinical Complex, Deesa, College of

Veterinary Science and Animal

husbandry, Sardarkrushinagar

Dantiwada Agricultural University,

Sardarkrushinagar, Gujarat, India

\section{Corresponding Author:}

Sahu AD

Department of Veterinary

Gynaecology \& Obstetrics, Dr. V. M.

Jhala Clinical Complex, Deesa,

College of Veterinary Science and

Animal husbandry,

Sardarkrushinagar Dantiwada

Agricultural University,

Sardarkrushinagar, Gujarat, India

\section{Clinical management of estral eversion in a dobermann bitch}

\author{
Chauhan PM, Sahu AD, Nakhashi HC, Jogdand DT and Sodagar BN
}

DOI: https://doi.org/10.22271/tpi.2020.v9.i3j.4522

\begin{abstract}
A 2.5 year old dobermann bitch was presented to veterinary clinics with owner complaint of protrusion of mass through vulva since 10 days and it was in heat about 2 weeks ago and mated subsequently. The mass was contaminated with dust and dirt. On clinical examination, protruded mass was involved everted cervix and vagina with presence of maggot wound at ventral aspect. The prolapsed mass was thoroughly washed with antiseptic solution and removed maggots. The mass was proper repositioned and replaced by using glass test tube. Purse string sutures were applied around the vagina with cotton thread. The animal was treated with LH analogue, antibiotic, analgesic and laxative for 3-5 consecutive days.
\end{abstract}

Keywords: Dobermann bitch, veterinary clinics, estral eversion

\section{Introduction}

Estral eversion commonly known as vaginal prolapse/vaginal hypertrophy/vaginal hyperplasia is referred to as the edematous enlargement of the vaginal tissue that occurs during oestrus or proestrus due to high serum estrogen ${ }^{[1]}$ and sometime may be confused with vaginal neoplasia, transmissible venereal tumor and venereal granuloma ${ }^{[2]}$. Almost $80 \%$ cases of cervico-vaginal prolapse is occurs in young bitch below 2 to 3 years of age in their first three estrous cycles ${ }^{[3]}$ and it also associated with parturition during prolonged labor or up to $48 \mathrm{~h}$ after fetal delivery ${ }^{[4]}$. The actual cause of prolapse is unknown in bitch but it may be due to excessive relaxation and stretching of pelvic musculature ${ }^{[5]}$, severe tenesmus and uterine disease, rough handling during parturition, genetic predisposition and aberrant connective tissue metabolism ${ }^{[6]}$. Beside this, it may cause due to increased amount of estrogen level during follicular phase of estrus ${ }^{[7]}$. It mainly during first estrus and it could be regressed in the luteal phase ${ }^{[1]}$. It usually reoccurred in 66 to $100 \%$ during subsequent estrus ${ }^{[7,8]}$. Further, prolapsing tissue promotes straining, which further increases the amount of prolapsed tissue ${ }^{[1]}$ which susceptible to trauma, laceration and ulceration, and can hinder the natural mating [9]. Therefore, present case a Dobermann bitch suffered with estral eversion ant its clinical management is reported.

\section{Case History and Observation}

A 2.5 years old Dobermann bitch was presented to Dr. V. M. Jhala Clinical Complex, Deesa with owner complaint that she was came in estrus 2 week ago and mated with healthy dog. Following mating, the mass was protruded through vulva was observed since 10 days. The mass was severely oedemated, congested and smeared with dust and dirt. Bitch was showed frequent straining and urinates normally. Physical parameters showed slightly deviated with subnormal rectal temperature $\left(98.8^{\circ} \mathrm{F}\right)$, elevated heart rate $(112 \mathrm{bpm})$ and slightly congested eye mucous membranes. On careful clinical examination of mass revealed that it was $360^{\circ}$ estral eversion of cervix and vagina (Fig.1). Maggot wound was present at ventral aspect of prolapsed mass on vagina. Vaginal smear showed increase numbers of intermediate cells, fewer numbers of neutrophils and erythrocytes were absent (Fig. 2). The bitch was observed the leucocytosis $\left(16.7 \times 10^{3} / \mu \mathrm{L}\right)$ along with neutrophilia $(82.80 \%)$.

\section{Clinical management}

The prolapsed cervico-vaginal tissue was washed with mild Potassium permanganate (PP) solution to remove the dust and durt (Fig.3). $2 \mathrm{ml}$ of Lignocaine hydrochloride (Lidocain ${ }^{\circledR}$ ) was given at lumbo-sacral epidural space to minimize the excessive straining (Fig. 4). 
The maggots were removed from small opening at ventral aspect of vuvla (Fig. 5). Then, applied the Lignocaine gel and Soframycin ointment topically on prolapsed mass to reduce the pain and prevent secondary bacterial infection, respectively. Applied the bandage over the severely oedemated mass and given minimum traction as well as squeezed with palm pressure which help in reduction in size of mass (Fig 6). Proper reposition and replacement was achieved by using $20 \mathrm{~cm}$ long glass tube having $3 \mathrm{~cm}$ in diameter along with bilateral pressure was applied by finger tips and palm to push the protruded mass in the pelvic cavity towards the ovarian end (Fig.7). Purse string sutures were taken using cotton thread (Fig.6) The bitch was administered with fluid therapy ( $250 \mathrm{ml}$ of normal saline), antibiotic (500 mg of Amoxycillun-Cloxacillin, IV; Intamox), analgesic ( $2 \mathrm{ml}$ of Meloxicam, IV; Meloxam) and Luxative (10 ml of Syrup Lactulose, PO) for 5 days. Injection of LH analogue (500 IU of Inj. Chorulon, IM) was given for 3 consecutive days. Sutures were removed on $10^{\text {th }}$ day and the bitch showed uneventful recovery.

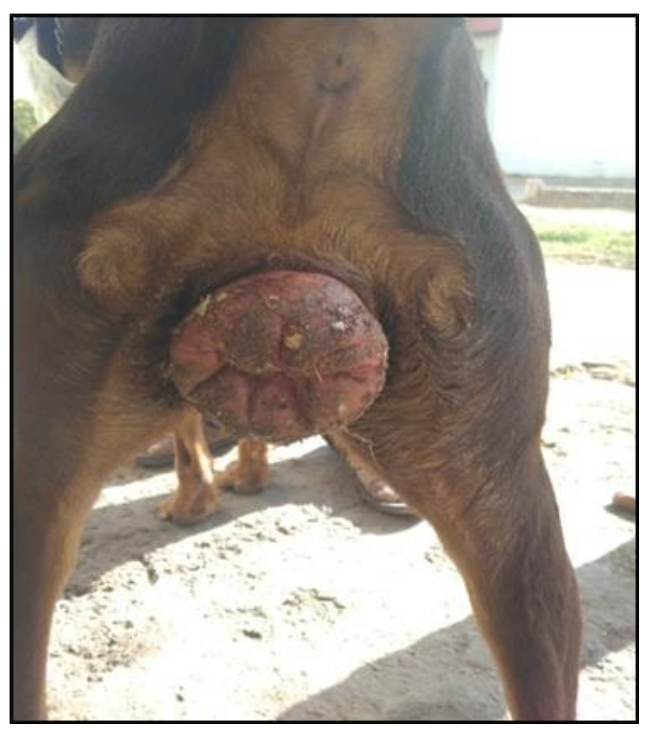

Fig 1: $360^{\circ}$ estral eversion in dobermann bitch

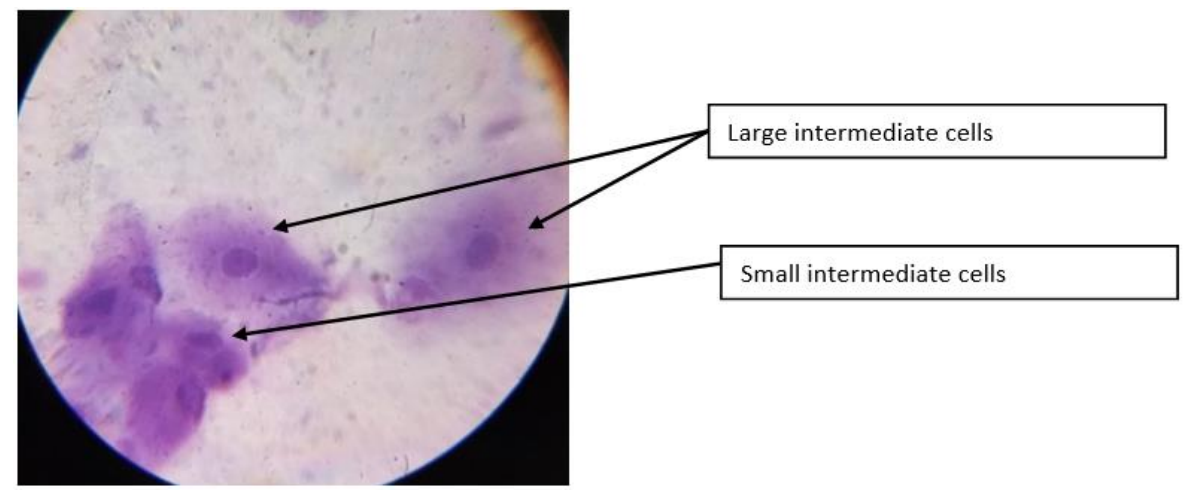

Fig 2: Vaginal cytology revealed intermediate cells

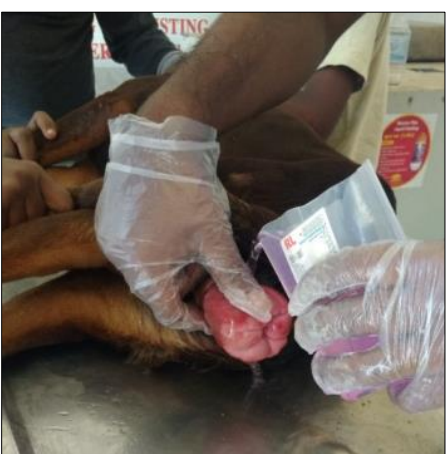

Fig 3: Washing of prolapsed mass with mild antiseptic solution of $\mathrm{KMnO}_{4}$

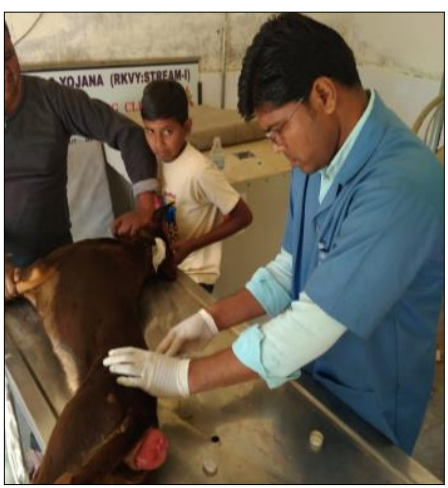

Fig 4: Lumbo-sacral epidural anesthesia using 1\% Lignocaine hydrochloride
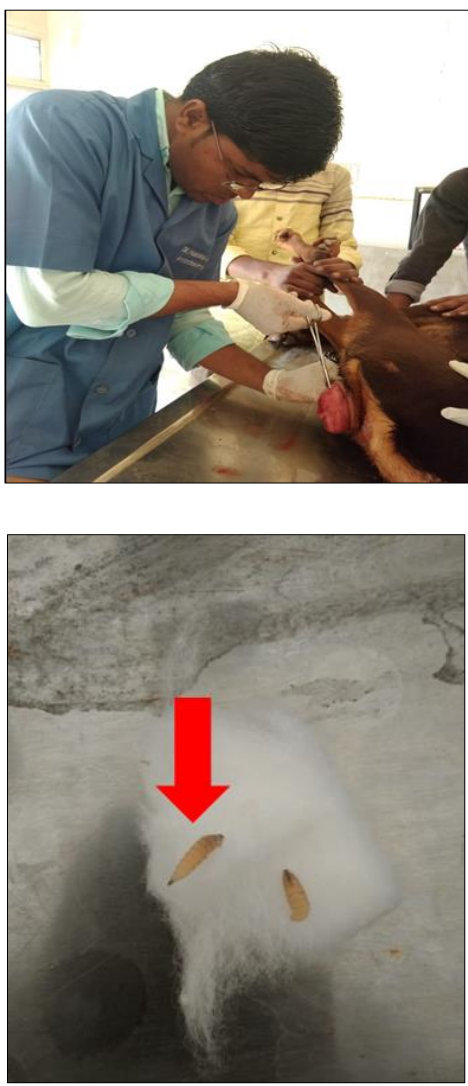

Fig 5: Removing the maggots from vaginal wound 

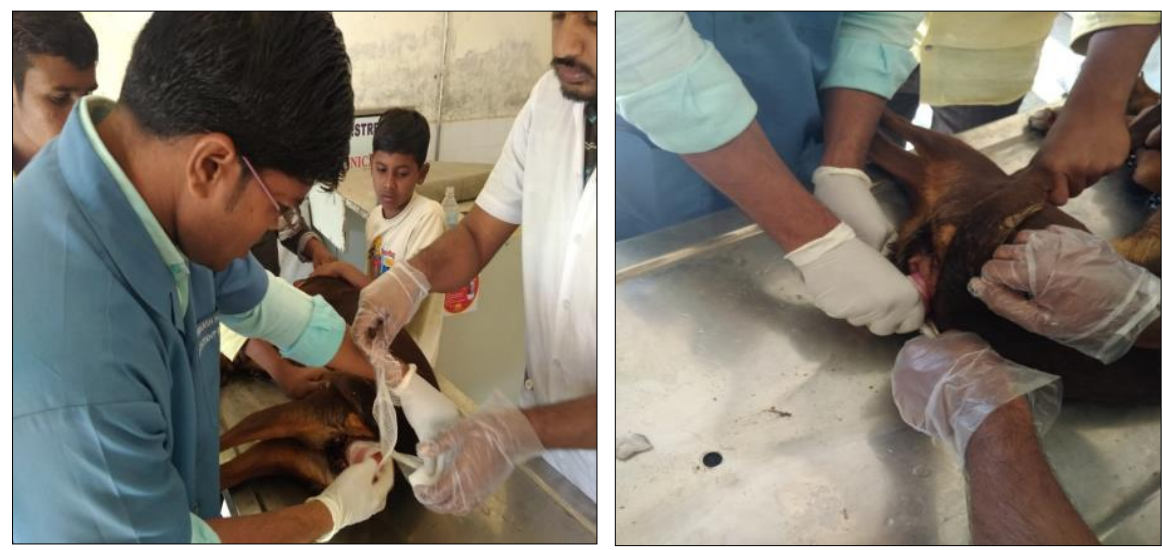

Fig 6: Applying a bandage and squeeze the mass by palm pressure
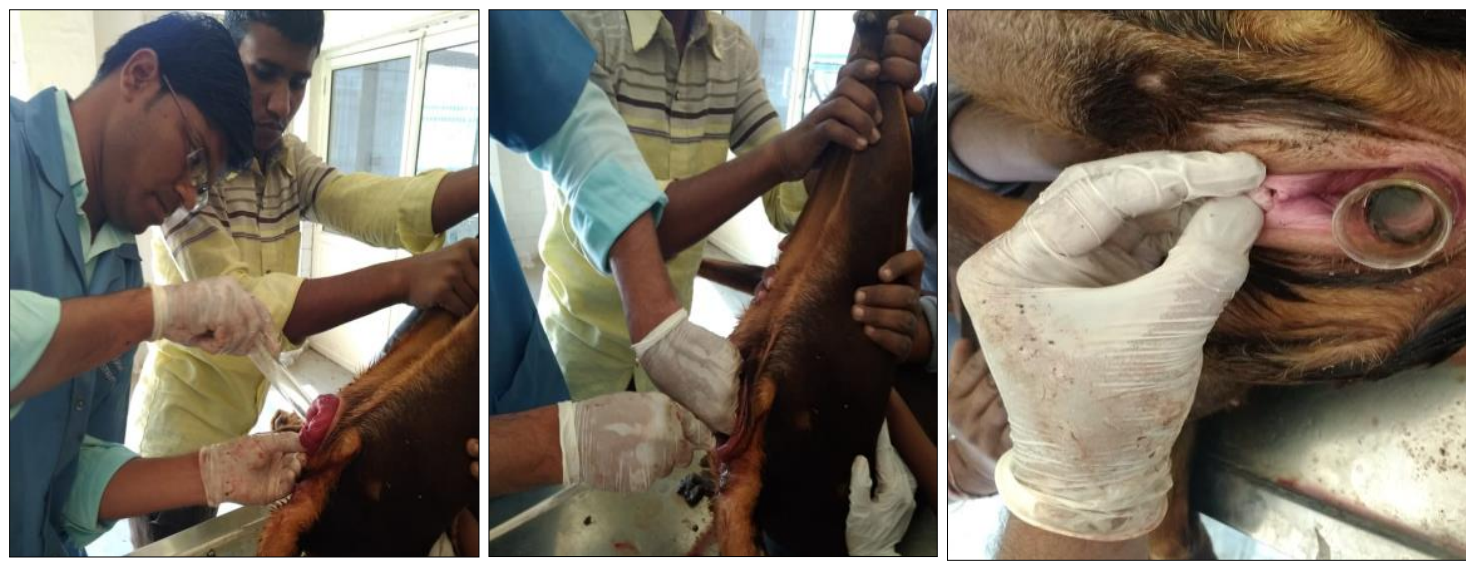

Fig 7: Use the glass tube to reposition and replacement of mass by uplifting the posterior region of bitch

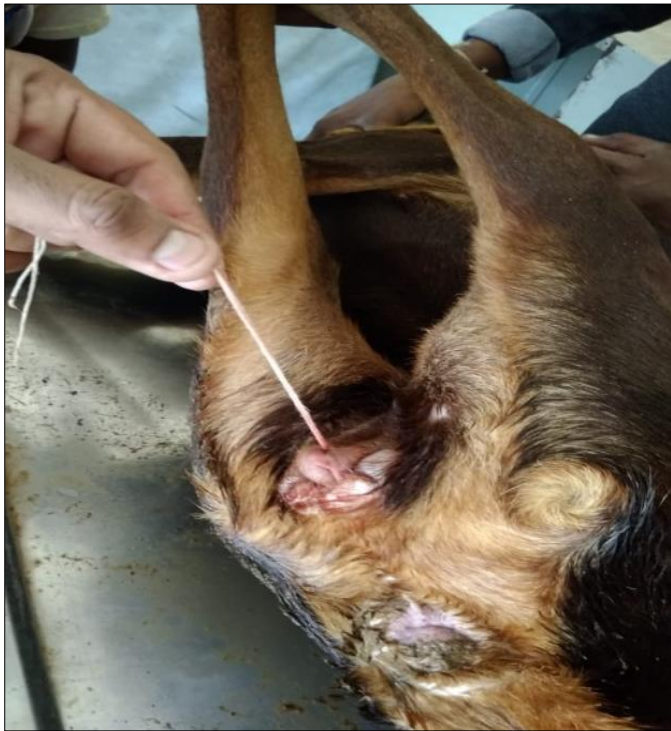

Fig 8: Purse string suture of vulva

\section{Result and discussion}

Estral eversion is commonly occured in bitches at proestrous and estrous phases between 1 to 4 years of age due increased estrogen concentration ${ }^{[10]}$. Regression of the protruded mass begins in late estrus to early diestrus, as serum estrogen returns to the normal basal level ${ }^{[8]}$. According to Feldman and Nelson [11], Doberman appears to be more prone to vaginal fold prolapsed and that may be due to hereditary weakness of the perivulvar tissue. Along with cervix and vagina, other organs were also involved in true vaginal prolapse ${ }^{[12]}$. Vaginal cytology is helps to identifying the stage of estrus cycle based on presence of different exfoliative cells ${ }^{[13]}$ but in present case, the bitch was in luteal phase on the basis of presence of intermediate cells, neutrophils and time lapsed for irreducible prolapsed. In present study, the squeezing of prolapsed mass by using a bandage as well as palm was greatly reduced the size without damaging the vaginal tissue. The use of glass test tube $(20 \mathrm{~cm}$ in length and $3 \mathrm{~cm}$ in diameter) was effectively to proper reposition and replacement of prolapsed mass with injury to the vaginal mucosa.

The protruded mucosa in prolonged case can be eventually become necrosed, inflamed and can easily be ruptured ${ }^{[2]}$. A high grade vaginal prolapse and vaginal hyperplasia in the bitch was managed successfully by modified technique for surgical excision without affecting the reproductive ability [14]. Sometime, ovariohysterectomy is also recommended as a prophylactic treatment and to avoid recurrence of vaginal prolapsed ${ }^{[15]}$. Medical treatment is not advised because a fold prolapse reoccurs frequently, if not treated surgically. Further, treatments with GnRH or hCG to induce premature ovulation and shortening of estrus cycle have been used with limited success ${ }^{[16]}$. In present study, a bitch was treated with $\mathrm{LH}$ analogue work effectively and prevented the reoccurrence of prolapsed mass in subsequent estrus. A successful management of true vaginal prolapsed in female grey hound was reported by Ahuja et al. ${ }^{[17]}$

\section{Conclusion}

The present case of estral eversion in dobermann bitch was successfully managed by managerial attempts along with hormonal therapy (LH analogue; Inj. Chorulon) without occurrence of prolapsed mass in subsequent estrus. 


\section{Acknowledgement}

We express our sincere thanks and gratitude towards Dean and Principal, College of Veterinary Science and A.H. for providing the necessary facilities at Veterinary Clinical Complex, Deesa to performed present study.

\section{References}

1. Fossum TW, Hedlund CS, Johnson AL. Small Animal Surgery. (3rd edn.). Mosby Publication, Missouri. 2007, p743

2. Suresh RV, Veena P, Sankar P, Dhana Lakshmi N, Sreelatha $\mathrm{CH}$, Kokila. Vaginal hyperplasia in a dog-A case report. Tamilnadu J Vet Anim Sci. 2011; 7(3):174175.

3. Ajadi TA, Ajayi OL, Adeniyi AA, Ajadi RA. Vaginal wall hyperplasia with fold prolapse in an eight-month-old cane corso dog. Bulgarian J Vet Med. 2016; 19(3):252258.

4. Arthur GH, Noakes DE, Pearson H. Veterinary Reproduction and Obstetrics. (7th edn.). Saunders, London, 1996.

5. Benesch F, Wright JG. Veterinary Obstetrics. Green world Publishers, Lucknow, 2001.

6. Ozyurtlu N, Kaya D. Unilateral uterine prolapsed in a cat. Turkish J Vet. Anim. Sci. 2005; 29:941-943.

7. Alan M, Cetin Y, Sendag S, Eski F. True vaginal prolapse in a bitch. Anim Reprod Sci. 2007; 100:411414.

8. Johnston SD, Root Kustritz MV, Olson PNS. Canine and feline theriogenology. Bellingham, USA: W.B. Saunders, 2001.

9. Gokula Krishnan M, Nagarajan I, Arunaman CS. Surgical management of vaginal hyperplasia and prolapse in a pug bitch Indo-Am. J Agric Vet Sci. 2014; 2:3-7.

10. Nak D, Nak Y, Yilmazbas G. First report of vaginal prolapse in an ovariohysterectomised bitch-A case report. Bull Vet Inst Pulawy. 2008; 52:397-398.

11. Feldman EC, Nelson RW. Vaginal defects, vaginitis and vaginal infection. In: Canine and Feline Endocrinology and Reproduction, 3rd edn, eds. W. B. Saunders, Philadelphia,], 2004, 901-918.

12. Wykes PM. Diseases of the vagina and vulva in the bitch. In: Morrow, D.A. (Ed.), Current Therapy in Theriogenology. W.B. Saunders Company, London, 1986, 476-481.

13. Turmalay L, Duro S, Lika E, Ceroni V. The hormonal control of estrus in bitches. J Anim Vet Adv. 2011; 10:2447-2449.

14. Ahuja AK, Dhindsa SS, Kumar A, Singh P. Surgical approach for vaginal hyperplasia and vaginal fold prolapse in bitch. J. Anim. Health Prod. 2018; 6(3):86-89.

15. Haji MM, Borpujari D, Talukdar DJ, Ahmed FA, Lalrintluanga K, Sarma K. Cystic endometrial hyperplasia - open pyometra complex in a female pug. Indian J Anim. Reprod. 2018; 39(1):63-65.

16. Rushmer RA. Vaginal hyperplasia and uterine prolapsed, In: Krik R.W.ed. Current veterinary therapy VII, small animal practice. Philadephia, 1980, 1222-1224.

17. Ahuja AK, Kumar S, Singh AK, Dhinds SS. Management of true vaginal prolapsed in bitch. International Journal of Environment, Agriculture and Biotechnology (IJEAB). 2017; 2(4):1660-1661. 